\title{
Experimental analysis of material properties of historical ceramic bricks and their potential current replacements
}

\author{
Z. Pavlík, T. Kulovaná, J. Žumár, M. Pavlíková \& R. Černý \\ Department of Materials Engineering and Chemistry, \\ Faculty of Civil Engineering, Czech Technical University in Prague, \\ Czech Republic
}

\begin{abstract}
The basic physical properties, mechanical parameters, hygric and thermal properties of two types of ceramic brick produced at the beginning of the $20^{\text {th }}$ century and a contemporary ceramic brick are studied, in order to analyze the applicability of the current bricks at the reconstruction of historical masonry. Among the basic physical properties, the bulk density, matrix density, total open porosity and pore size distribution are analyzed. The mechanical performance is characterized by the bending strength, compressive strength and dynamic Young's modulus. The moisture and salt solution transport is studied using a free water or salt solution uptake experiment where the penetration of either distilled water or $1 \mathrm{M} \mathrm{NaCl}$ water solution is observed. The capability to accumulate water vapour is studied by a dynamic vapour sorption device. Thermal parameters are measured using a transient pulse method. The experimental results show that the analyzed current ceramic brick is suitable for the reconstruction works on historical buildings.

Keywords: historical masonry, ceramic bricks, basic physical properties, mechanical properties, hygric and thermal properties.
\end{abstract}

\section{Introduction}

During the last decades, the preservation of architectural heritage has been the subject of rising interest of scientists, architects, engineers and archaeologists, making it into an interdisciplinary research area. When damaged historical masonry needs to be restored with the substitution of bricks, stone block and 
mortar, a good characterisation of both new and old material lets us forecast the durability of the whole material system. In addition to the necessary aesthetic aspect, the familiarity with the physical properties is crucial to maintain equilibrium with adjoining materials. Here, also chemical and physicochemical aspects must be considered [1]. Additionally, the historical understanding is not just to analyse and preserve objects, but also to investigate the knowledge and skills used to produce and use them [2].

Brick masonry constitutes a significant part of the construction materials found in historical buildings. Burnt ceramic bricks were first used in Mesopotamia for a long time for watertight constructions, such as water troughs or pipes, and for more vulnerable parts of the buildings, such as the frames of openings or the facings of large monuments [3]. Greeks and Romans used bricks much later as tiles and roof decorations for waterproof covering and as protection for the ends of the roof timbers [4]. Additionally, crushed or finely ground bricks called as "Horasan" in Turkey, "Surkhi" in India, "Homra" in Arabic countries and "Cocciopesto" in Roman times were used as aggregates in the manufacturing of lime mortars and plasters since ancient times [5]. These mortars and plasters made by mixing crushed bricks with lime set in the presence of water and have high mechanical strength. Together with building stone the bricks were the most important materials in the Gothic epoch. Typical examples of the Gothic complex brick architecture can be found for example in Northern Europe, where the ceramic bricks were used not only for residential houses, but also for religious architecture.

The development of brick manufacturing in Czech countries can be dated into the $14^{\text {th }}$ century, whereas the production assortment comprised standard brick blocks, floor slabs, roof coverings, stove tiles, tile coverings, etc. However, the burnt brick was used for more important and climatically exposed buildings because of its price. Up to the end of the $17^{\text {th }}$ century, the most popular building materials were, together with stone $[6,7]$, unburnt clay bricks. In the time period between the $18^{\text {th }}$ and $20^{\text {th }}$ century, a substantial number of walled buildings on the Czech territory was built using burnt ceramic bricks.

The level of brick decay in masonry differs widely, and in many cases it requires partial or full replacement [8]. Here, the selection of compatible materials for the replacement of original bricks is crucial, in order to avoid damage to the historical structure. On this account, this paper examines two historical ceramic bricks and one new, poorly burnt ceramic brick which all were produced in the Czech Republic, in order to identify the applicability of the newly produced brick in the renovation of historical masonry.

\section{Experimental}

\subsection{Studied materials}

Two different types of historical bricks from the tenement houses in Prague built at the beginning of the $20^{\text {th }}$ century were chosen as the representative materials for typical masonry of the end of $19^{\text {th }}$ and first half of the $20^{\text {th }}$ century in the 
Czech Republic. The contemporary ceramic brick was a product of the brick factory Polom, Ltd. (Czech Republic). All three materials were poorly burnt and highly heterogeneous.

\subsection{Basic physical properties}

Among the basic material properties, bulk density, matrix density and total open porosity were determined. Bulk density was accessed on the gravimetric principle using the sample dimensions measured by a digital length meter and the dry mass of the sample. For this measurement, 5 cubic samples of side $100 \mathrm{~mm}$ were used. The matrix density was determined using helium pycnometry. On the basis of bulk density and matrix density measurements, the total open porosity was calculated [9]. The relative expanded uncertainty of the applied testing method was 5\%.

\subsection{Pore size distribution}

For the measurement of pore size distribution, Mercury Intrusion Porosimetry (MIP) was applied, using the porosimeters Pascal 140 and Pascal 440 (Thermo Scientific). At the evaluation of the measured data, the circular cross section of capillaries was assumed, whereas the mercury contact angle was assumed to be $130^{\circ}[10]$.

\subsection{Mechanical properties}

Mechanical properties of investigated bricks were characterized by the compressive strength, bending strength and dynamic Young's modulus. The bending strength was determined on prismatic samples having dimensions 40 $\mathrm{mm} \times 40 \mathrm{~mm} \times 160 \mathrm{~mm}$. The compressive strength was measured on the fragments of samples from the bending strength testing, whereas the loading area was $40 \mathrm{~mm}$ x $40 \mathrm{~mm}$. Young's modulus was measured on dynamic principle using the ultrasonic pulse method. In the experiments, the samples were prisms having dimensions of $40 \mathrm{~mm} \times 40 \mathrm{~mm} \times 160 \mathrm{~mm}$, and the measurements were performed in longitudinal direction. The ultrasonic pulse method is based on the measurement of travel time of ultrasonic wave launched from the device and passing through the material. For the measurement a DIO 562 device working on the frequency of $50 \mathrm{KHz}$ was used [11].

\subsection{Moisture transport properties}

For the characterization of liquid water transport in the tested materials, the sorptivity concept was used. On this account, a free water intake experiment [12] that represents the simplest technique for the analysis of the ability of porous materials to absorb water and transport it by capillary forces was performed. Using this experiment, the water transport in the studied materials was characterized by water absorption coefficient $A_{w}\left(\mathrm{~kg} / \mathrm{m}^{2} \mathrm{~s}^{1 / 2}\right)$ and sorptivity $S_{w}\left(\mathrm{~m} / \mathrm{s}^{1 / 2}\right)$. For each studied material, 5 samples were tested, having the cubic 
shape of side $50 \mathrm{~mm}$. The relative uncertainty of the applied automatic measurement method was $5 \%$. Together with the investigation of distilled water transport, also the penetration of $1 \mathrm{M} \mathrm{NaCl}$ water solution $\left(A_{\mathrm{NaCl}}, S_{\mathrm{NaCl}}\right)$ was studied. Since the historical masonry is usually exposed to the harmful salt action, the knowledge of salt transport parameters represents a significant information. On the basis of water and $1 \mathrm{M} \mathrm{NaCl}$ solution absorption coefficient, the corresponding values of moisture diffusivity $\kappa\left(\mathrm{m}^{2} / \mathrm{s}\right)$ were calculated using Eq. (1),

$$
\kappa=\left(\frac{A_{w}}{w_{\text {sat }}}\right)^{2},
$$

where $w_{\text {sat }}\left(\mathrm{kg} / \mathrm{m}^{3}\right)$ is the saturated moisture content [13].

\subsection{Sorption and desorption isotherms}

In order to evaluate the interaction of researched materials with water vapour coming from high relative humidity environment, measurement of sorption and desorption isotherms was done. Sorption and desorption isotherms describe the thermodynamic relationship between the relative humidity of materials environment and its equilibrium moisture content at constant temperature and pressure. For the measurement, DVS-Advantage device (Surface Measurement Systems Ltd.) was used. The humidity range of the applied DVS instrument was $0-98 \%$ with the accuracy $\pm 0.5 \%$. The samples were firstly dried in a vacuum drier at $60^{\circ} \mathrm{C}$ and during the cooling they were kept in desiccators. The experiments were performed at $20^{\circ} \mathrm{C}$, whereas the samples were exposed to the following relative humidity profile: $0 ; 20 ; 40 ; 60 ; 80 ; 98 \%$. The instrument operated in $\mathrm{dm} / \mathrm{dt}$ mode (mass variation over time) to decide when equilibrium was reached [14]. A fixed dm/dt value of $0.00004 \%$ per min was selected for all relative humidity segments. The sample mass varied from 3.7 to $5.5 \mathrm{~g}$.

\subsection{Thermal properties}

Thermal conductivity $\lambda(\mathrm{WmK})$, thermal diffusivity $a\left(\mathrm{~m}^{2} / \mathrm{s}\right)$ and volumetric heat capacity $C_{v}\left(\mathrm{~J} / \mathrm{m}^{3} \mathrm{~K}\right)$ were measured using the transient pulse device ISOMET 2114 (Applied Precision, Ltd.) which applies a dynamic measurement method. The time period of the thermal conductivity measurements is thus reduced to approximately 10 - 15 minutes. The measurement is based on the analysis of the temperature response of the studied material to heat flow pulses. The heat flow is induced by electrical heating using a resistor heater having a direct thermal contact with the surface of the sample. The reproducibility of ISOMET 2114 for the thermal conductivity measurement is $3 \%$ of reading $+0.001 \mathrm{~W} / \mathrm{mK}$ and for volumetric heat capacity $3 \%$ of reading $+1 \cdot 10^{3} \mathrm{~J} / \mathrm{m}^{3} \mathrm{~K}$. The measurement accuracy is for thermal conductivity in the range of $0.015-0.7 \mathrm{~W} / \mathrm{mK}$ equal to $5 \%$ of reading $+0.001 \mathrm{~W} / \mathrm{mK}$. The accuracy of the volumetric heat capacity measurement is $15 \%$ or reading $+1.10^{3} \mathrm{~J} / \mathrm{m}^{3} \mathrm{~K}$ in the range of $4.0 \cdot 10^{4}-4.0 \cdot 10^{6}$ $\mathrm{J} / \mathrm{m}^{3} \mathrm{~K}$. 


\section{Results and discussion}

Basic physical properties of researched ceramic bricks are summarized in Table 1. Here, the historical materials are marked as $\mathrm{BH} 1, \mathrm{BH} 2$, and the current brick produced in the Polom brick factory as BP. Both historical bricks exhibited similar basic physical properties, whereas the differences where within the range of the measuring error. From the quantitative point of view, all the tested materials showed high total open porosity. Although the porosity of new brick was lower compared to the original historical materials, its value was also relatively high so that one can assume a satisfactory compatibility of this brick with historical masonry materials.

Table 1: Basic physical properties of researched ceramic bricks.

\begin{tabular}{|c|c|c|c|}
\hline Material & $\begin{array}{c}\text { Bulk density } \\
\left(\mathrm{kg} / \mathrm{m}^{3}\right)\end{array}$ & $\begin{array}{c}\text { Matrix density } \\
\left(\mathrm{kg} / \mathrm{m}^{3}\right)\end{array}$ & $\begin{array}{c}\text { Total open porosity } \\
\left(\% \mathrm{~m}^{3} / \mathrm{m}^{3}\right)\end{array}$ \\
\hline BH1 & 1691 & 2659 & 36.4 \\
\hline BH2 & 1713 & 2664 & 35.2 \\
\hline BP & 1888 & 2688 & 29.8 \\
\hline
\end{tabular}

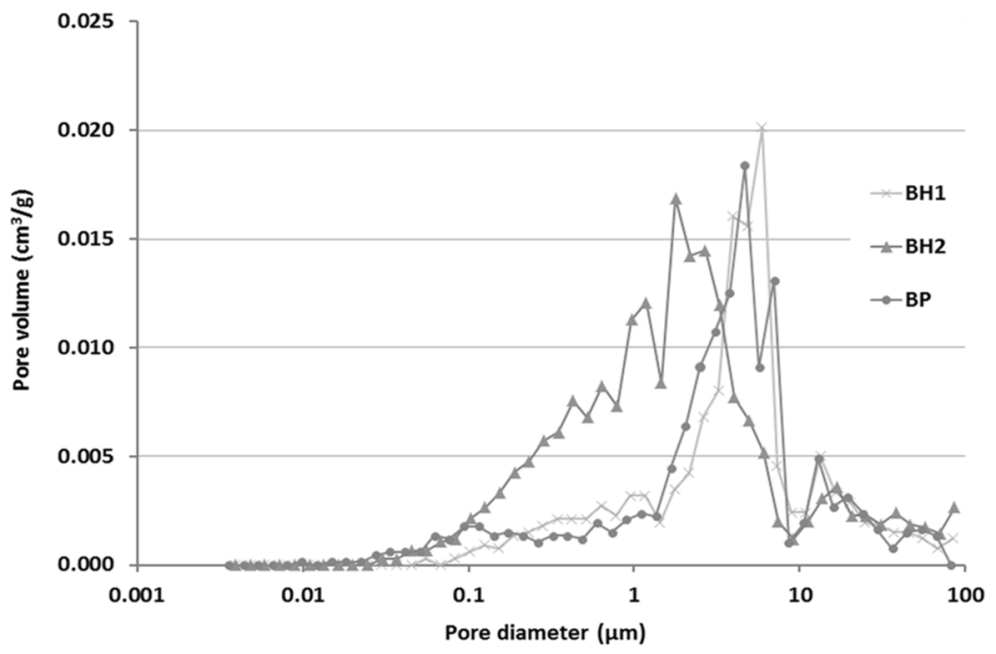

Figure 1: $\quad$ Pore size distribution measured by MIP.

The pore size distribution data measured by MIP is given in Fig. 1. This data must be considered as informative only, because of the materials high inhomogeneity. In MIP, only small samples having a mass of about $2 \mathrm{~g}$ were measured, whereas the sample sizes were even smaller than some particles of non-plastic materials incorporated in the researched historical bricks. The materials $\mathrm{BH} 1$ and $\mathrm{PB}$ exhibited the highest volume of pores in the pore size 
interval of $1.35-8.55 \mu \mathrm{m}$, contrary to the brick BH2, which had the majority of pores in the range of 0.1 to $6 \mu \mathrm{m}$. However, all the identified pores can be classified as capillary, allowing transport of both liquid and gaseous moisture. Also in this case the compatibility of newly produced brick PB with historical materials could be considered as good in general.

Mechanical properties are summarized in Table 2. One can see that the newly manufactured brick BP had much better mechanical parameters than both historical materials. This finding is related to the combination of two effects. First, the mechanical properties of bricks are highly affected by firing temperature, method of production, physical, chemical and mineralogical composition of the raw materials [15]. In particular, the varying firing temperature and firing time have important effects on the brick quality [16]. The lower firing temperature at the production of historical bricks and higher inhomogeneity of raw materials could be responsible for the observed lower mechanical strength of historical materials, as compared to the well homogenized raw mixture prepared in new bricks manufacturing. Second, the historical materials inbuilt approximately 100 years in the tenement houses underwent climatic loading, thus they were exposed to harmful disruptive effects. On this account, one can assume their partial degradation and damage that probably resulted in the decrease of mechanical parameters.

Table 2: $\quad$ Mechanical properties of tested bricks.

\begin{tabular}{|c|c|c|c|}
\hline Material & $\begin{array}{c}\text { Compressive strength } \\
(\mathrm{MPa})\end{array}$ & $\begin{array}{c}\text { Bending strength } \\
(\mathrm{MPa})\end{array}$ & $\begin{array}{c}\text { Young's modulus } \\
(\mathrm{GPa})\end{array}$ \\
\hline $\mathrm{BH} 1$ & 6.9 & 1.9 & 4.6 \\
\hline $\mathrm{BH} 2$ & 13.3 & 2.1 & 6.8 \\
\hline $\mathrm{BP}$ & 26.3 & 3.2 & 8.2 \\
\hline
\end{tabular}

Table 3: Water and salt solution transport properties.

\begin{tabular}{|c|c|c|c|c|}
\hline Material & $\begin{array}{c}\mathrm{A}_{\mathrm{w}} \\
\left(\mathrm{kg} / \mathrm{m}^{2} \mathrm{~s}^{1 / 2}\right)\end{array}$ & $\begin{array}{c}\mathrm{S}_{\mathrm{w}} \\
\left(10^{-4} \mathrm{~m} / \mathrm{s}^{1 / 2}\right)\end{array}$ & $\begin{array}{c}\mathrm{A}_{\mathrm{NaCl}} \\
\left(\mathrm{kg} / \mathrm{m}^{2} \mathrm{~s}^{1 / 2}\right)\end{array}$ & $\begin{array}{c}\mathrm{S}_{\mathrm{NaCl}} \\
\left(10^{-4} \mathrm{~m} / \mathrm{s}^{1 / 2}\right)\end{array}$ \\
\hline BH1 & 0.271 & 2.715 & 0.259 & 2.580 \\
\hline BH2 & 0.265 & 2.655 & 0.245 & 2.440 \\
\hline $\mathrm{BP}$ & 0.250 & 2.505 & 0.236 & 2.351 \\
\hline
\end{tabular}

The results of water and $1 \mathrm{M} \mathrm{NaCl}$ solution uptake experiments are given in Table 3. The corresponding data of calculated moisture diffusivity is presented in Table 4. The investigated hygric parameters were in a qualitative agreement with the data of total open porosity and MIP. Typically, higher porosity was related to higher water absorption coefficient, sorptivity, and moisture diffusivity. Quantitatively, the obtained results were similar for all studied materials, whereas the $\mathrm{NaCl}$ water solution transport was slightly slower, as compared to the distilled water intake. 
Table 4: Moisture diffusivity measured for penetration of water $\kappa_{\mathrm{w}}$ and $1 \mathrm{M}$ $\mathrm{NaCl}$ water solution $\kappa_{\mathrm{NaCl}}$.

\begin{tabular}{|c|c|c|}
\hline Material & $\begin{array}{c}\kappa_{\mathrm{w}} \\
\left(10^{-7} \mathrm{~m}^{2} / \mathrm{s}\right)\end{array}$ & $\begin{array}{c}\kappa_{\mathrm{NaCl}} \\
\left(\mathrm{m}^{2} / \mathrm{s}\right)\end{array}$ \\
\hline BH1 & 6.98 & 5.88 \\
\hline BH2 & 5.32 & 5.07 \\
\hline BP & 4.98 & 4.17 \\
\hline
\end{tabular}

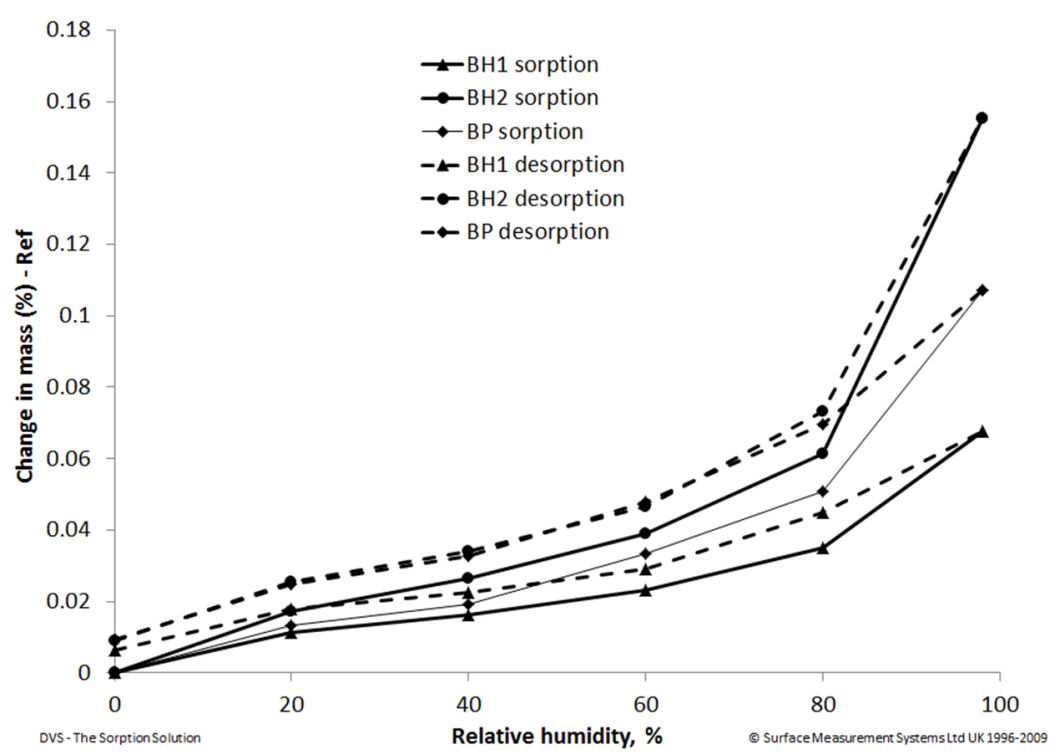

Figure 2: $\quad$ Sorption and desorption isotherms measured by DVS device.

The sorption and desorption isotherms measured by DVS device are presented in Fig. 2. All studied materials exhibited low water vapour storage in the relative humidity range up to $80 \%$. For higher relative humidity values, a certain increase in moisture storage could be observed. However, the corresponding moisture content was lower than 0.18 mass $\%$ what is negligible from a practical point of view of the materials performance in real climatic conditions. At the measured desorption isotherms, significant hysteretic effects were identified. The hysteresis data is given in Table 5. The highest hysteresis showed the new type of ceramic brick. This can be assigned to the fact that this material was not exposed to such long climatic exposure as historical bricks. On this account, more free sites for the adsorption of water vapour molecules on the pore walls were available. 
Table 5: Hysteresis in moisture storage - change in mass $\%$.

\begin{tabular}{|c|c|c|c|}
\hline Relative humidity (\%) & BH1 & BH2 & BP \\
\hline 20 & 0.00647 & 0.0081 & 0.0117 \\
\hline 40 & 0.00604 & 0.0074 & 0.0137 \\
\hline 60 & 0.00600 & 0.0076 & 0.0145 \\
\hline 80 & 0.00985 & 0.0120 & 0.0187 \\
\hline
\end{tabular}

Thermal properties are presented in Table 6 . The researched bricks had similar volumetric heat capacity, and the heat transport parameters were in a qualitative agreement with total open porosity values. Also in this case, the materials inhomogeneity should be taken into account since the measured values differed for the specific locations of the measuring sensor on the brick surface.

Table 6: Thermal properties of studied bricks.

\begin{tabular}{|c|c|c|c|}
\hline Material & $\begin{array}{c}\lambda \\
(\mathrm{W} / \mathrm{mK})\end{array}$ & $\begin{array}{c}\mathrm{C}_{\mathrm{v}} \\
\left(10^{6} \mathrm{~J} / \mathrm{m}^{3} \mathrm{~K}\right)\end{array}$ & $\begin{array}{c}\mathrm{a} \\
\left(10^{-6} \mathrm{~m}^{2} / \mathrm{s}\right)\end{array}$ \\
\hline $\mathrm{BH} 1$ & 0.41 & 1.37 & 0.30 \\
\hline $\mathrm{BH} 2$ & 0.45 & 1.38 & 0.33 \\
\hline $\mathrm{BP}$ & 0.50 & 1.38 & 0.36 \\
\hline
\end{tabular}

\section{Conclusions}

The investigations on the applicability of newly produced type of ceramic brick for the reconstructions of historical brick masonry were presented. The new ceramic brick exhibited a satisfactory compatibility with the original historical materials from the point of view of its basic physical, mechanical, hygric and thermal properties. Therefore, it can be recommended for the renovation of masonry of historical buildings built of similar kind of bricks.

\section{Acknowledgement}

This research has been supported by the Ministry of Culture of the Czech Republic, under project No DF12P01OVV030.

\section{References}

[1] López-Arce, P., Garcia-Guinea, J., Gracia, M., Obis, J., Bricks in historical buildings of Toledo City: characterisation and restoration. Materials Characterization, 50, pp. 59-68, 2003.

[2] Vandiver, P., The role of materials research in ceramics and archeology. Annual Review of Materials Research, 31, pp. 373-385, 2001.

[3] Radivojevic, A., Kurtovic-Folic, N., Evolution of brick and brick masonry in the early history of its use in the region of today's Serbia. Journal of Materials in Civil Engineering, 18(5), pp. 692-699, 2006. 
[4] Özkaya, Ö.A., Böke, H., Properties of Roman bricks and mortars used in Serapis temple in the city of Pergamon. Materials Characterization, 60, pp. 995-1000, 2009.

[5] Böke, H., Akkurt, S., İpekoğlu, B., Uğurlu, E., Characteristics of brick used as aggregate in historic brick-lime mortars and plasters. Cement and Concrete Research, 36, pp. 1115-1122, 2006.

[6] Pavlík, Z., Vejmelková, E., Pavlíková, M., Keppert, M., Černý, R., Characterization of Building Stones Involved in Historical Masonry. Advanced Materials Research 324, pp. 388-391, 2011.

[7] Kočí, V., Maděra, J., Fořt, J., Žumár, J., Pavlíková, M., Pavlík, Z., Černý, R., Service Life Assessment of Historical Building Envelopes Constructed Using Different Types of Sandstone: A Computational Analysis Based on Experimental Input Data. The Scientific World Journal, 2014(1), pp. 1-12, 2014.

[8] Elert, K., Cultrone, G., Navarro, C.R., Pardo, E.S., Durability of bricks used in the conservation of historic buildings - influence of composition and microstructure. Journal of Cultural Heritage, 4, pp. 91-99, 2003.

[9] Pavlíková, M., Pavlík, Z., Keppert, M., Černý, R., Salt transport and storage parameters of renovation plasters and their possible effects on restored buildings' walls. Construction and Building Materials, 25(3), pp. 1205-1212, 2011.

[10] Pavlík, Z., Trník, A., Keppert, M., Pavlíková, M., Žumár, J., Černý, R., Experimental Investigation of the Properties of Lime-Based PlasterContaining PCM for Enhancing the Heat-Storage Capacity of Building Envelopes. International Journal of Thermophysics, 35(3), pp. 767-782, 2014.

[11] Pavlík, Z., Keppert, M., Pavlíková, M., Fořt, J., Michalko, O., Černý, R., MSWI bottom ash as eco-aggregate in cement mortar design. WIT Transactions on Ecology and the Environment, IV(165), pp. 127-138, 2012.

[12] Hall, C., Hoff, W.D., Water Transport in Brick, Stone and Concrete, Taylor and Francis, U.K., 2002.

[13] Kumaran, M.K., Moisture Diffusivity of Building Materials from Water Absorption Measurements. Journal of Building Physics, 22(4), pp. 349355, 1999.

[14] Pavlík, Z., Žumár, J., Medved', I., Černý, R., Water vapor adsorption in porous building materials: experimental measurement and theoretical analysis. Transport in Porous Media, 91, pp. 939-954, 2012.

[15] Bhatnagar, J.M., Goel, R.K., Thermal changes in clay products from alluvial deposits of the Indo-Gangetic plains. Construction and Building Materials, 16, pp. 113-122, 2002.

[16] Karaman, S., Ersahin, S., Gunal, H., Firing temperature and firing time influence on mechanical and physical properties of clay bricks. Journal of Scientific \& Industrial Research, 65, pp. 153-259, 2006. 